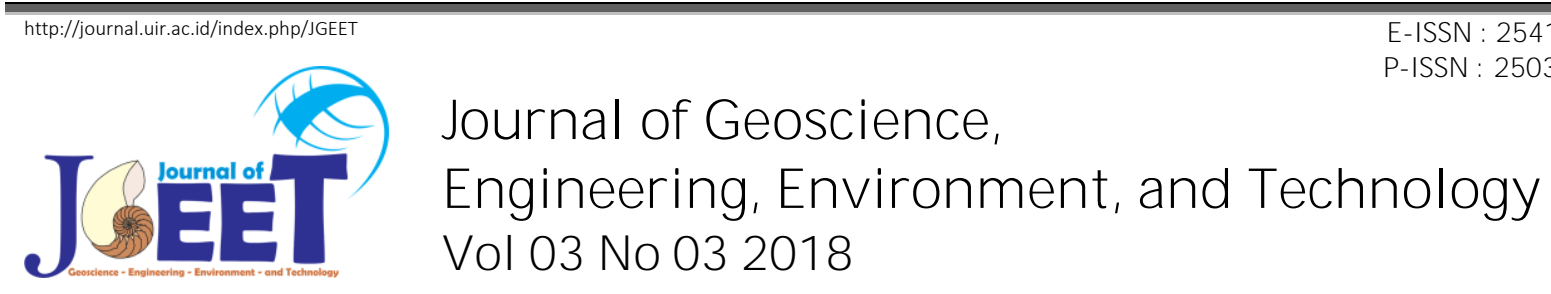

RESEARCH ARTICLE

\title{
Assessment of Microgravity Anomalies of Soil Structure for Geotechnical 2D Models
}

\author{
A. Arisona ${ }^{1,2, *}$, Mohd Nawawi $^{2}$, Amin E. Khali il, ${ }^{2,3}$, Abdullahi Abdulrahman ${ }^{4}$ \\ ${ }^{1}$ Geophysical Department, Haluoleo University, 93232, Kendari, Indonesia \\ ${ }^{2}$ School of Physics, Universiti Sains Malaysia, 11800, Penang, Malaysia \\ ${ }^{3}$ Geology Dept., Faculty of Science, Helwan University, Egypt, Mesir. \\ ${ }^{4}$ Department of Physics, Abubakar Tafawa Balewa University, Bauchi, Nigeria.
}

\author{
* Corresponding author : arisona1972@hotmail.com \\ Tel.: +6014607608 \\ Received: July 16, 2018; Accepted: Aug 31, 2018. \\ DOI: 10.24273/jgeet.2018.3.3.2058
}

\section{Abstract}

A microgravity investigation on bedrock topography was conducted at Maluri Park in Kuala Lumpur, Malaysia. The study characterized the subsurface structure to delineate soil structure for the geotechnical application. Cross-section modelling of the residual anomaly generated the Maluri Bouguer Anomaly model for test site. The 2D microgravity models produced the contour map, displaying the characterization due to density contrast in rock types while mapping the subsurface geological structure at different depths. Moreover, a synthetic model was initiated with the assumption of lateral distance on the left and right sides taken at $50 \mathrm{~m}$ and a depth of $60 \mathrm{~m}$. The results of modeling confirmed that the soil and rock type composition on models test site, i.e: topsoil $(1.1 \mathrm{~g} / \mathrm{cm} 3)$, soil $(1.8 \mathrm{~g} / \mathrm{cm} 3)$, clay $(1.63 \mathrm{~g} / \mathrm{cm} 3)$, gravel $(2.0 \mathrm{~g} / \mathrm{cm} 3)$, sand $(1.7 \mathrm{~g} / \mathrm{cm} 3)$, shale $(2.40 \mathrm{~g} / \mathrm{cm} 3)$, sandstone $(2.76 \mathrm{~g} / \mathrm{cm} 3)$ and limestone $(2.9 \mathrm{~g} / \mathrm{cm} 3)$. The 2D gravity synthetic model show a good match with the observed microgravity data.

Keywords: Microgravity, Anomaly, Soil, Density contrast, Modelling.

\section{Introduction}

The microgravity method is widely used for a geophysical investigation, especially in the detection of cavities, karsts phenomena, subsoil irregularities, or hidden landfills. microravity method's application in geotechnical investigation appreciates lateral variations in subsurface structure generated by density contrasts (Ebbing et al., 2001). In many cases, deep or small-scale heterogeneities generating low amplitude anomalies have to be detected, and the reliability of further interpretation requires highly accurate measurements, carefully corrected for any quantifiable disturbing effects (Debeglia and Dupont, 2002).

Generally, microgravity for a sphere or cylinder is the same as for a point mass, Talwani (1960) gave an equation (1) in the form:

$$
\Delta g=\frac{G m z}{\left(x^{2}+y^{2}\right)^{3 / 2}}
$$

$\Delta \mathrm{g}$ is component of gravitational attraction measured by a gravimeter (mGal); $\mathrm{x}$ is the horizontal distance from the observation point to a point directly above the centre of the sphere $(\mathrm{m}) ; \mathrm{z}$ is the vertical distance from the surface to the centre of the sphere (m). $G$ is universal gravitational constant (i.e.: $G=6.67$ $x 10^{-11} \mathrm{Nm}^{2} / \mathrm{kg}^{2}$ ). y is vertical distance from the surface to the centre of the sphere or cylinder $(\mathrm{m})$.
In actuality, one term in this expression for each point mass. If there are $N$ point masses, this equation can be written more compactly as (equation 2),

$$
\Delta g=\sum_{i=1}^{N} \frac{G m z i}{\left((x-d i)^{2}+z_{i}^{2}\right)^{3 / 2}}
$$

The microgravity method can be a relatively easy geophysical technique, in data acquisition, processing, and interpretation. It requires only simple but precise data processing, and for detailed studies, the determination of a Park's elevation is the most difficult because it is time-consuming (Lilie, 1999; Kearey et al., 2002). However, the technique has good depth penetration when compared to ground penetrating radar, high frequency electromagnetic and DCresistivity techniques and is not affected by the high conductivity values of near-surface clay-rich soils. Additionally, lateral boundaries of subsurface features can be easily obtained in particular through the measurement of the derivatives of the gravitational field (Kearey et al., 2002).

Modeling microgravity data in profile form is useful for the calculation of the depth of various features and can be done by either forward or inverse algorithms. In similarity with other geophysical methods, the interpretation of microgravity data is non-unique 
because many possible models could result in the same microgravity anomaly. Constraints, such as depths to rock obtained from useful information, rock densities, or other geophysical interpretations, are required during the modeling process to remove the ambiguity. This study focused on microgravity models using physical parameters that are robust in characterizing soil structures and soil properties.

\section{Site Description and Geology}

The study site is the area around Taman Maluri, Jalan Chereas, Kuala Lumpur (KL) (Fig. 1). The bedrock within the Maluri area is a Limestone formation. $\mathrm{KL}$ Limestone is well known for its highly unusual karstic features (Tan, 2005). Furthermore, due to the inherent karstic features of limestone bedrock, the depth of the limestone bedrock is highly irregular (Samsudin, 2003).The overburden soils above KL Limestone are mainly silty sand. The thickness of overburden soils varies significantly due to the irregular topography of the limestone bedrock.

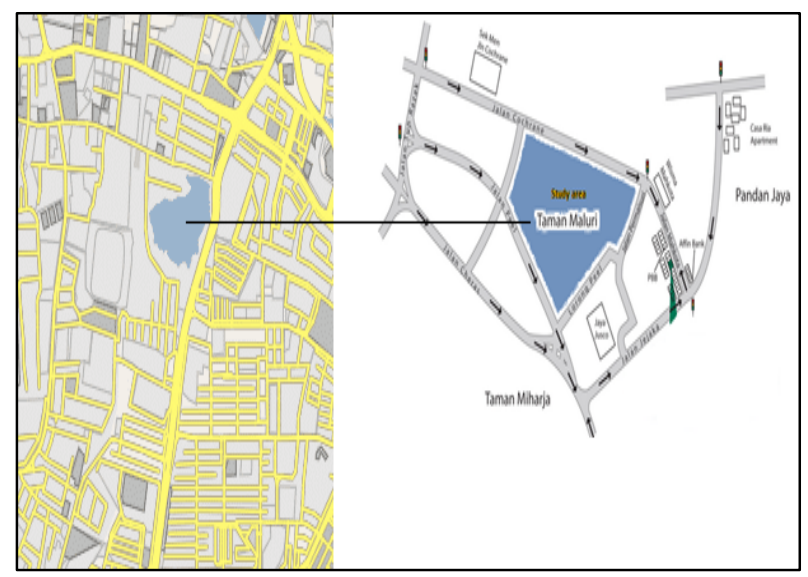

Figure 1. Slices of Maluri Park Map that was obtained from Google Map

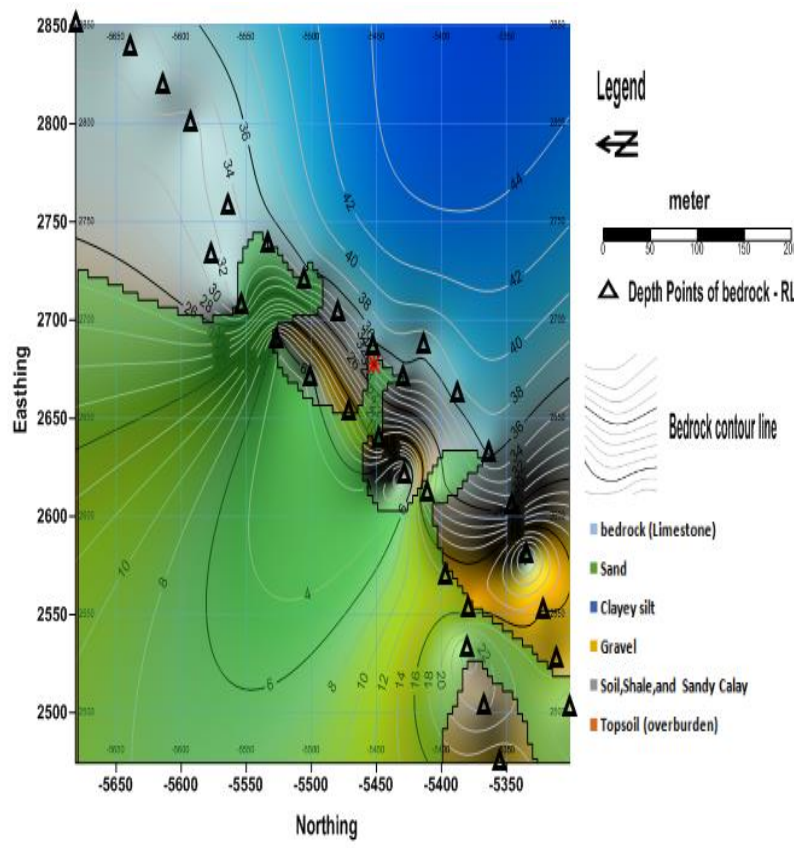

Figure 2. Bedroc KL Contour Map at Maluri Park
Based on the results of 2 boreholes $(\mathrm{BH})$ in the area, the bedrock is determined to be between $31 \mathrm{~m}$ to $34 \mathrm{~m}$ depth. The soil in the Maluri area is light greyish-brown in colour and mostly sandy. This trends showed that thickness of overburden soil varied between $3 \mathrm{~m}$ and 5 $\mathrm{m}$ from the surface. On the other hand, the residual soil underline by limestone bedrock (Fig.2) is mainly loose fine-grained materials. They are described and named according to the fine-grained naming method such as silty clay, clayey silt, silty sand, and sandy clay.

\section{Methodology}

Microgravity data from the survey area were processed using Surfer ${ }^{\circledR 13}$ software which reduced Bouguer anomaly values at each Park of the microgravity survey. Fig.3 shows that the modeling has been well constrained because the parameters required to obtained the bedrock topography were well defined from the $\mathrm{BH}$ data.

The post-processing procedure checked the microgravity instrument corrections for latitude and longitude, diurnal variations and instrument drift using base Park polynomial drift values and relative elevation.This procedure is merged with the respective microgravity Park topographic survey data which is being modeled. The density value of $1.8 \mathrm{~g} / \mathrm{cm} 3$ was used to calculate the Bouguer correction for all survey data sets.

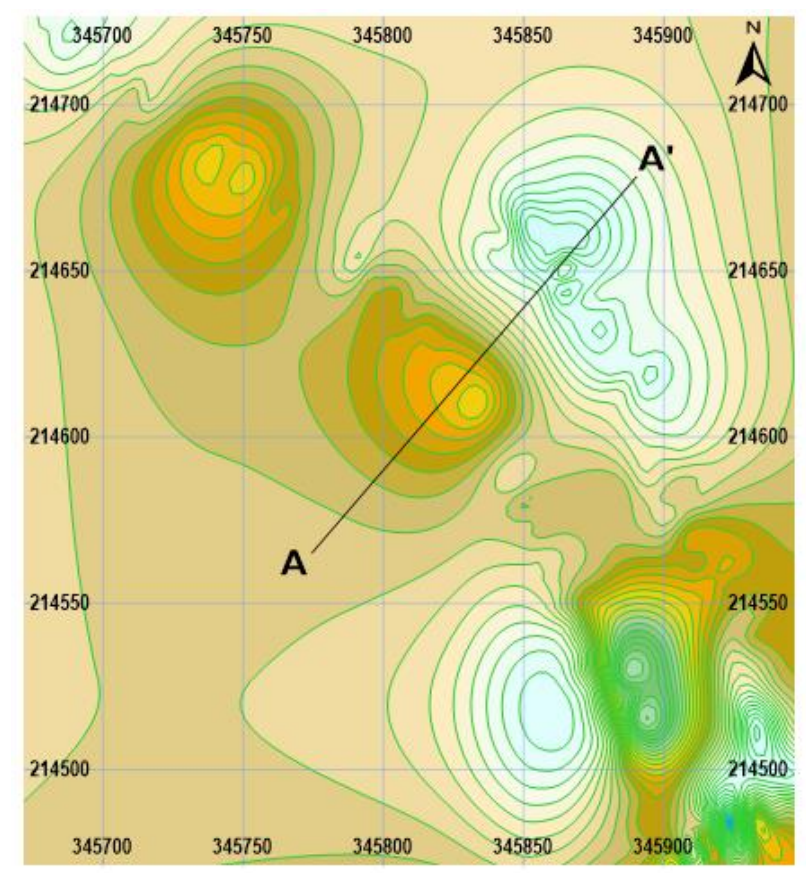

Figure 3. Residual microgravity contour map at Taman Maluri compiled from topography and Bouguer anomalies at testsite.

Subsequent processing was the elevation correction to address the variation in data points due to the topography (Tajuddin,2004). This evaluation is necessary for the 2D geotechnical modeling (Pringle,2012). Furthermore, the removal of regional values (low frequency and high amplitude) to express the residual anomalies (high frequency and low amplitude) was performed using the upward 
continuation approach. The modeling of the residual anomaly was generated in Cooper TM Grav2Dc v.2.10 software. However, qualitative interpretation using geological maps are used only as additional information.

\section{Results and Discussion}

\subsection{Gravity overview of Maluri bedrock}

The results of this investigation confirmed earlier $\mathrm{BH}$ results which indicated the presence of the cavities. However, the uneven distribution and clustering of the data necessitate the use of an interpolation algorithm to create a uniformly spaced grid. All data processing in the contour map were generated with Cooper ${ }^{\mathrm{TM}}$ Surfer ${ }^{\circledR} 13$ software. The survey results were represented in contour maps for delineating anomalies varying from negative to positive value. According to Kamal et al. (2010), negative values are interpreted as low density subsurface layers and for the possibility of the existence of cavities. Table 1 presents the density of rock types that were reviewed in this study. The typically have densities ranging from $1.0 \mathrm{gr} / \mathrm{cm}^{3}$ to 2.90 $\mathrm{g} / \mathrm{cm}^{3}$ (Telford, 2010).

The qual itative interpretation explains the anomaly by geological and geophysical information. On this basis, the geological structure and distribution of masses of different densities may be delineated. The difference in density values can be correlated to divergent material types such as soil, rock, and cavities.

\subsection{Interpretation of 2D geotechnical models for microgravity anomaly at Maluri site}

Maluri site consists of lowlands in the north and highlands in the south, and this pattern is confirmed by the microgravity anomalies with the lower regions displaying higher microgravity values. Fig 4 show results of the microgravity data of Maluri site for the residual anomalies. The profile displays the tendency of response towards positive anomalies, and yet it was not significant to influence the microgravity anomaly around model test site. In additional, Fig.4 shows the residual microgravity anomaly at model test site, characterized by negative values, probably due the inhomogeneous geo-materials consisting of a mixture of clay and silt with grain sizes which is from fine to medium.

Fig. 5 show results of the $2 \mathrm{D}$ geotechnical model generated with Cooper ${ }^{\mathrm{TM}}$ Grav2Dc v.2.10 software that was adopted from extracts of residual anomaly the results of profiles test site.

The curves for the model at the test site confirmed the product of a minute misfit of $4.44 \%$ between calculated curves with observed curves. Furthermore, model calculated microgravity confirmed density contrast at model test site as shown in Table 2 . The results of synthetic models showed that there are eight rock types from the microgravity profiles; topsoil (1.1 $\mathrm{g} / \mathrm{cm} 3)$, soil $(1.8 \mathrm{~g} / \mathrm{cm} 3)$, clay $(1.63 \mathrm{~g} / \mathrm{cm} 3)$, gravel $(2.0$ $\mathrm{g} / \mathrm{cm} 3)$, sand $(1.7 \mathrm{~g} / \mathrm{cm} 3)$, shale $(2.40 \mathrm{~g} / \mathrm{cm} 3)$, sandstone $(2.76 \mathrm{~g} / \mathrm{cm} 3)$ and limestone $(2.9 \mathrm{~g} / \mathrm{cm} 3)$. Moreover, the synthetic model shows that inhomogenities in the variation of the subsurface material and density contrast in the covered layers.

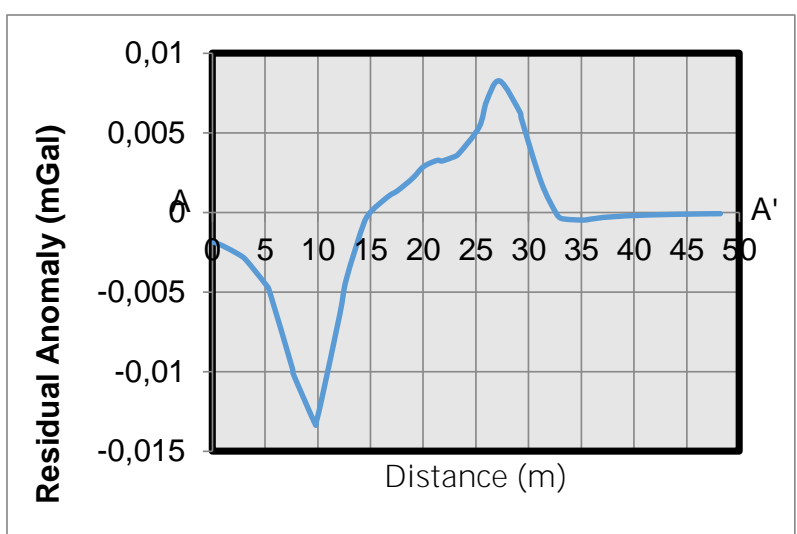

Fig. 4. Results of gravity field measurements at Maluri Site for profiles test site using extracted techniques from anomaly contour maps.

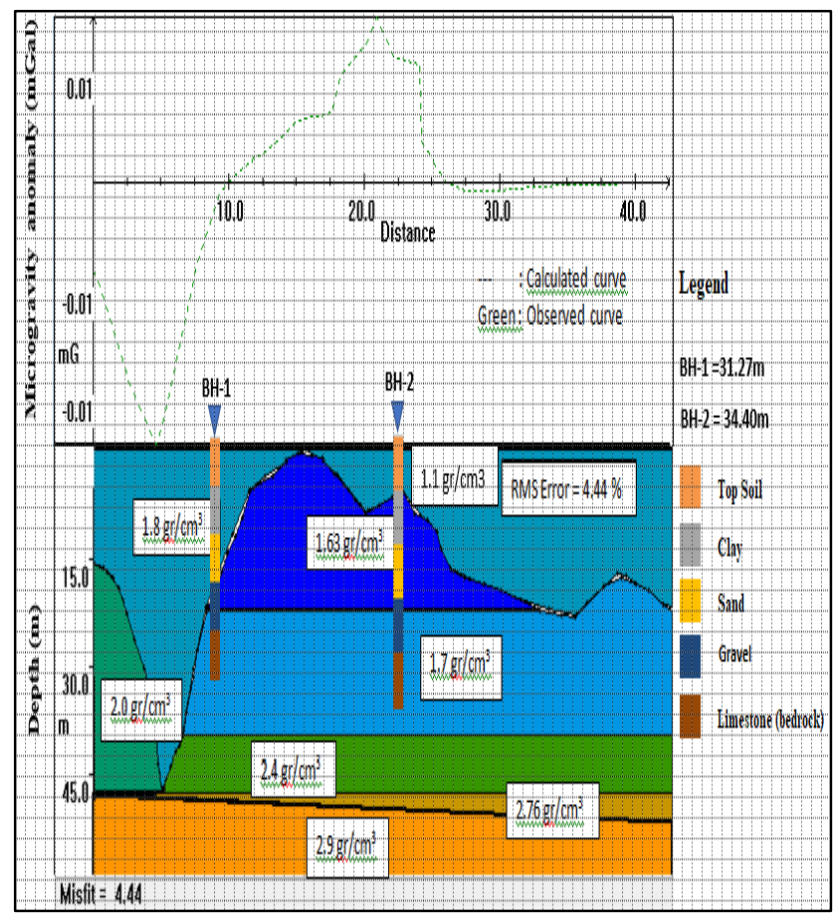

Figure 5 Geotechnical 2D models site test- 1 of the survey area (top) with corrected gravity data and model-calculated gravity (bottom). Models show best-fit corrected gravity data with RMS Error $=4.44 \%$

\section{Conclusion}

The gravity field data showed the good impression of the 2D geotechnical models. The result obtained from the Grav2Dc v.2.10 software correlates the modelcal culated gravity and the corrected gravity data in site tests have minimal percentage errors. The results of modeling showed that that there are eight rock types from the gravity profiles; topsoil $\left(1.1 \mathrm{~g} / \mathrm{cm}^{3}\right)$, soil $(1.8$ $\left.\mathrm{g} / \mathrm{cm}^{3}\right)$, clay $\left(1.63 \mathrm{~g} / \mathrm{cm}^{3}\right)$, gravel $\left(2.0 \mathrm{~g} / \mathrm{cm}^{3}\right)$, sand $(1.7$ $\left.\mathrm{g} / \mathrm{cm}^{3}\right)$, shale $\left(2.40 \mathrm{~g} / \mathrm{cm}^{3}\right)$, sandstone $\left(2.76 \mathrm{~g} / \mathrm{cm}^{3}\right)$ and limestone $\left(2.9 \mathrm{~g} / \mathrm{cm}^{3}\right)$.

Utilization of extracted technique characterized the density contrast due rock type and mapped subsurface geological structure at different depth. 
Models of microgravity distribution in the ground could be useful for the mapping of variations in soil composition. The changes in gravity anomaly observed throughout the sections were due to the heterogeneities in the composition of the subsurface materials and density contrasts in the study area.

Table 1 Rock types density values

\begin{tabular}{ccc}
\hline Rock Type & $\begin{array}{c}\text { Density range } \\
\left(\mathrm{gr} / \mathrm{cm}^{3}\right)\end{array}$ & $\begin{array}{c}\text { Average } \\
\text { (gr/cm }\end{array}$ \\
\hline $\begin{array}{c}\text { Overburden } \\
\text { (Topsoil) }\end{array}$ & - & 1.10 \\
Soil & 1.20 to 2.40 & 1.92 \\
Clay & 1.63 to 2.60 & 2.21 \\
Gravel & 1.70 to 2.40 & 2.00 \\
Sand & 1.70 to 2.30 & 2.00 \\
Sandstone & 1.61 to 2.76 & 2.35 \\
Shale & 1.77 to 3.20 & 2.40 \\
Limestone & 1.93 to 2.90 & 2.55 \\
Dolomite & 2.28 to 2.90 & 2.70 \\
\hline
\end{tabular}

Table 2. Estimated density contrast from model-calculated gravity for the 2D geotechnical model at Model test site

\begin{tabular}{cc}
\hline Density $\left(\mathrm{g} / \mathrm{cm}^{3}\right)$ & Rock Type \\
\hline 1.10 & Top soil (overburden) \\
1.80 & Soil \\
1.63 & Clay \\
2.00 & Gravel \\
1.70 & Sand \\
2.40 & Shale \\
2.76 & Sandstone \\
2.90 & Limestone \\
\hline
\end{tabular}

* RMSError $=4.44 \%$

\section{Acknowledgements}

First of all, we thank to the Directorate General of Higher Education (DGHE) of Indonesia who has giving us scholarship. The authors thank Jamaluddin Othman of Owner/Principal Geophysicist for providing the borehole results and gravity data of Maluri Park area. The field support from technical staff of Geophysics Programme, School of Physics, Universiti Sains Malaysia is highly appreciated.

\section{References}

Debeglia, N., Dupont, F., 2002. Some critical factors for engineering and environmental microgravity investigations. Journal of Applied Geophysics 50, 435-454. https://doi.org/10.1016/S0926-9851(02)00194-5

Ebbing, J., Braitenberg, C., Götze, H.-J., 2001. Forward and inverse modelling of gravity revealing insight into crustal structures of the Eastern Alps. Tectonophysics 337, 191 208. doi:10.1016/s0040-1951(01)00119-6

Kamal, H., Taha, M, and Al-Sanad, S.,2010. Environmental Engineering and Geotechnics, GeoShanghai 2010 International Conference. (accessed 02.03.17)

Kearey, P., Brooks, M., Hill, I., 2011. An introduction to geophysical exploration. Blackwell Publishing, Malden, MA.

Lillie, R.J., 1999. Whole earth geophysics: an introductory textbook for geologists and geophysicists. Prentice Hall, Upper Saddle River, NJ. https://nla.gov.au/anbd.biban13624882

Pringle, J.K., Styles, P., Howell, C.P., Branston, M.W., Furner, R. Toon, S.M., 2012. Long-term time-lapse microgravity and geotechnical monitoring of relict salt mines, Marston, Cheshire, U. K. Geophysics 77. https://doi.org/10.1190/geo2011-0491.1
Samsudin, Hj., T., 2003. A microgravity survey over deep limesone bedrock, Geological Society of Malaysia, Bulletin 46, pp 201-208 (accessed 12.11.16). http://archives.datapages.com/ data/ geological-societyof-malaysia/bulletins/ 046/ 046001/ pdfs/ 201.htm

Tan, S., M. ,2005. Karstic Features of Kuala Lumpur Limestone. Bulletin of the Institution of Enginner Malaysia, June 2005, 6 -11. (accessed 08.02.17)

Tajuddin, A. and Lat, C. N., 2004. Detecting subsurface voids using the microgravity method-A case study from Kuala Lipis, Pahang, Geological Society of Malaysia, Bulletin 48, p. 31 - $35 . \quad$ (accessed 11.01.16) http://archives.datapages.com/data/geological-societyof-malaysia/bulletins/ 048/ 048001/ pdfs/31.htm

Telford, W.M., Geldart, L.P., Sheriff, R.E., 2010. Applied geophysics. Cambridge Univ. Press, Cambridge.

Talwani, M., Ewing, M., 1960. Rapid Computation of Gravitational Attraction of Three-Dimensional Bodies of Arbitrary Shape. Geophysics 25, 203-225. https://doi.org/10.1190/1.1438687

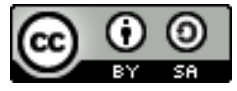

(C) 2016 Journal of Geoscience, Engineering, Environment and Technology. All rights reserved. This is an open access article distributed under the terms of the CC BY-SA License (http://creativecommons.org/licenses/by-sa/4.0/). 